\title{
Unresectable Breast Carcinoma
}

National Cancer Institute

\section{Source}

National Cancer Institute. Unresectable Breast Carcinoma. NCI Thesaurus. Code C158752.

Breast carcinoma that is not amenable to surgical resection. 